\title{
Finite Element Analysis of Semi-Solid Die-Casting Technology of Magnesium Alloy Hook Based on AnyCasting
}

\author{
Hanwu Liu \\ Dep. of Mechanical and Electrical Engineering, North \\ China Institute of Science and Technology \\ Sanhe, Hebei, 065201, China \\ hanwu-liu@sohu.com
}

\author{
Fan Feng \\ Sch. of Materials Science and Engineering, Southeast \\ University, Nanjing, Jiangsu, 211189, China \\ 642246717@qq.com
}

\author{
Junming Liu \\ Dep. of Mechanical and Electrical Engineering \\ North China Institute of Science and Technology \\ Sanhe, Hebei, 065201, China \\ Junminghiu@ncist.edu.cn
}

\begin{abstract}
According to the die-coasting forming principle, several ingates of different sizes and semi-solid die-casting technology parameters were designed in this paper. The solid modeling of the casting was created based on Pro/E software. The simulation of the filling process of semi-solid die-casting of Magnesium alloy hook used in the train was made by using the finite element analysis software AnyCasting. And the apparent viscosity test of semi-solid magnesium alloy AZ91D was done by using a self-designed coaxial double-barrel rheometer in order to investigate the changing laws of apparent viscosity under different shear temperatures and shear rates. The study results show that the apparent viscosity of Magnesium alloy AZ91D decreased obviously with the shear strength increasing at $42 \%$ of the solid-phase ratio, which is suitable for the semi-solid forming of Magnesium alloys. To avoid creating air holes, shrinkages and other defects in castings, the thickness of ingates should be appropriately increased to make the semi-solid metal slurry flow in the way of laminar flow much easily when filling the mold. The semi-solid magnesium alloy AZ91D has good rheological properties under the conditions of mixing temperature $570^{\circ} \mathrm{C}$ and shear rate $88.85 s-1$. The quality of castings is ideal when switching the speed at the time of low injection speed $0.1 \mathrm{~m} / \mathrm{s}$, high injection speed $1 \mathrm{~m} / \mathrm{s}$ and the filling rate up to $65 \%$.
\end{abstract}

Keywords-Semi-solid, Apparent viscosity, Magnesium alloy, Mould design, Numerical simulation

\section{INTRODUCTION}

Magnesium alloys is the lightest structure metal, which has a great significance to decrease the self-weight, energy consumption and environmental pollution when using Magnesium alloys to the railway locomotive and other components. As a kind of green engineering materials, Magnesium alloys has a lot of excellent properties, the market demand of it is growing rapidly in electronics, automobiles, aerospace and other areas. Nowadays, the die casting technology is the main technology of magnesium alloys forming, however, the traditional die-casting technology of Magnesium alloy has the same problems as the forming of other die-casting alloys which the gases existing in the cavity or created by the die-casting coating can't be squeezed out successfully. The gases dissolve in the magnesium alloys or form a lot of high-pressure micro stomata which distribute dispersedly in the die-castings. But the process of rheological or thixotropic semi-solid forming of Magnesium alloys is very contributive to eliminate these defects, and can improve the quality of the die-castings.

The numerical simulation for the process of filling form and solidification can help to forecast all kinds of defects and its size, position and time of occurrence of die-castings effectively before actual casting productions, so that researchers can find countermeasures to deal with the problems before pouring, which makes certain of the quality of castings, shortens the cycle of trial-production and decreases the cost of productions. In this article, we studied the semi-solid die-casting technology of Magnesium alloy hooks used in trains, made the modeling of the die-casting mould design with the geometric modeling software PRO/E, and did numerical simulations for the semi-solid casting process of magnesium alloy hooks combining with the finite element analysis software Anycasting, which provides the theoretical basis for the optimization design of the technological parameters of the Magnesium alloy components.

\section{EXPERIMENT TESTS OF RHEOLOGICAL PROPERTY OF AZ91D ALLOY}

In order to control the forming process of semi-solid magnesium alloy, and produce Magnesium alloy parts with higher quality, we need to understand the essence of semi-solid Magnesium alloy AZ91D. The rheological law and histogenesis of semi-solid Magnesium alloy are the main factors of the most essential details. The researches for the rheological properties of semi-solid Magnesium AZ91D 
were carried out with the self-designed coaxial double tube rheology. The experiment results show that the relationship between solid-phase scores and apparent viscosity. We can find that the solid-phase score has great influence on the apparent viscosity. The apparent viscosity increases with the increase of the solid-phase score. The apparent viscosity rises rapidly at the beginning before the solid-phase score is more than some critical value. The different shearing rates correspond with different critical values of solid-phase scores, but the critical value is almost $42 \%$.

We can also find that the apparent viscosity decreases with the increase of shearing rate. However, the regular pattern is different of the reduction of the apparent viscosity of Magnesium alloy AZ91D with the increase of shearing rate under the conditions of different solid-phase scores. The alloy's apparent viscosity decreases from $0.17 \mathrm{~s}^{-1}$ when the shearing rate is from $35.54 \mathrm{~Pa}^{*} \mathrm{~s}$ to $0.11 \mathrm{~s}^{-1}$ when the shearing rate is $115.51 \mathrm{~Pa}^{*} \mathrm{~s}$ under the condition of $13 \%$ solid-phase scores. The apparent viscosity decreases with the increase of shearing rates, but the decrease trend is not obvious. In the same time, the experiment results also show that the shearing rate is higher, and the rheological property of melt alloy is better. Therefore, It's not good to pursue too high shearing rate one-sidedly. In a general way, there exists an optimal shear rate. We choose $88.85 \mathrm{~s}^{-1}$ as the shearing rate during the slurry making in the test.

\section{NUMERICAL SIMULATION FOR THE RHEO-DIECASTING AND FILLING PROCESS}

It's very complex how the filling process of semi-solid metal is. In order to research the filling rule of casting's cavity of semi-solid rheo-diecasting process of Magnesium alloy and liquid die casting, we choose the injection speed and ingate dimension which are the two factors relative significantly to the influence during the filling process of cavity. We use casting simulation software Anycasting to do the numerical simulation for semi-solid AZ91D alloy paste rheo-diecasting and filling process. And different thicknesses of ingates and different injection speeds (in the high-speed injection phase) and switching time of high-speed injection were designed in the study.

1) The influence of injection speeds in the low-speed injection phase and the thickness of ingates: Figure. 1 is the mathematical modeling figure of a Magnesium alloy hook. Figure.2, Figure. 3 and Figure. 4 show the speed of semi-solid metal slurry's filling process when the thickness of ingate is $7 \mathrm{~mm}$, and the injection speed in the low-speed injection phase is $0.4 \mathrm{~m} / \mathrm{s}, 0.25 \mathrm{~m} / \mathrm{s}, 0.1 \mathrm{~m} / \mathrm{s}$ respectively. Each Figure is the simulated result when the speed switching time is filling mold rate $65 \%$ and already filling mold $40 \%$.

From the figures, it was found that the speed of the metal slurry through the ingate is too higher, this causes the metal slurry to hit the hook base up and side directly, and produces eddy current in the base cavity. In the filling state, metal slurry are parceled by gases, which cause some defects, such as casting internal clip gas, and loose, this will seriously affect the quality of the semi-solid die-casting parts.

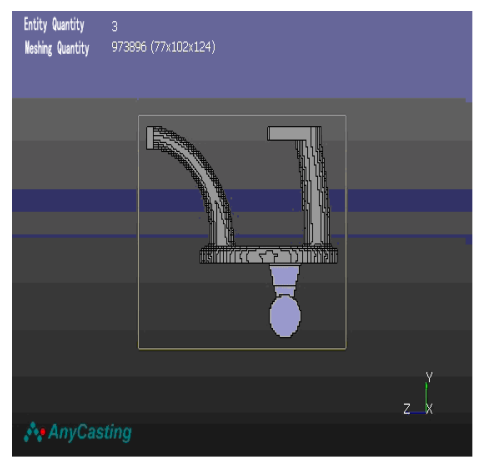

Figure 1. Mathematical model of semi-solid metal slurry of Magnesium alloy hook

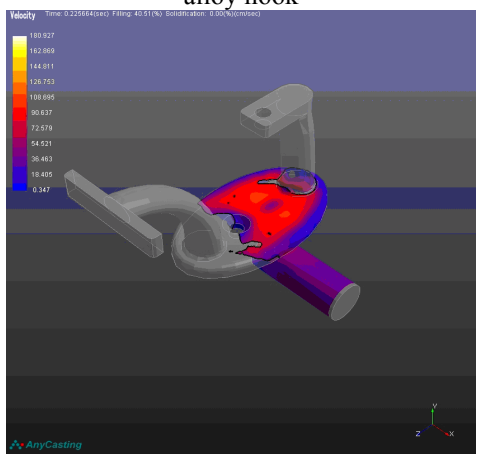

Figure 2. The speed of filling process when thickness of ingates is $7 \mathrm{~mm}$, the injection speed is $0.25 \mathrm{~m} / \mathrm{s}$

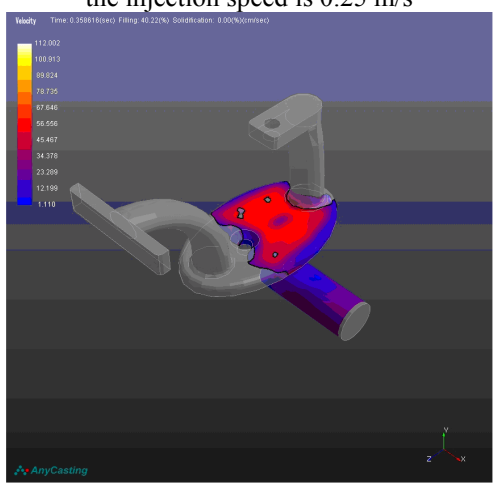

Figure 3. The speed of filling process when thickness of ingate is $7 \mathrm{~mm}$, the injection speed is $0.4 \mathrm{~m} / \mathrm{s}$

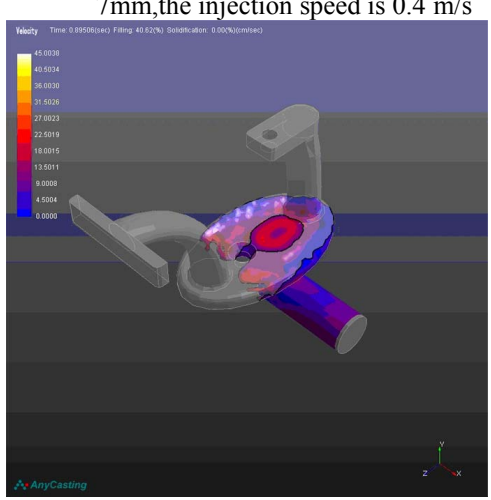


Figure 4. The speed of filling process when thickness of ingates is $7 \mathrm{~mm}$, the injection speed is $0.1 \mathrm{~m} / \mathrm{s}$

When the injection speed is $0.1 \mathrm{~m} / \mathrm{s}$, metal slurry accumulates at the cavity of foundation through the ingate, and the filling mold is smooth. This filling state is good for the release of gases, and will reduce the tendency of the parcel gases. So it is an ideal filling state.

When the thickness of ingate is $2 \mathrm{~mm}$ shown in Figure. 5, the injection speed is $0.1 \mathrm{~m} / \mathrm{s}$ with filling mold rate of $40 \%$, this causes the thickness of ingate thicker and thicker, metal slurry's filling speed through the ingate is higher, and the wrapped gas phenomenon in ingate places takes place easily. As a result, when using semi-solid metal die-casting, instead of the experience that taking smaller value of the thickness of ingate during liquid metal die-casting, we should take larger value.

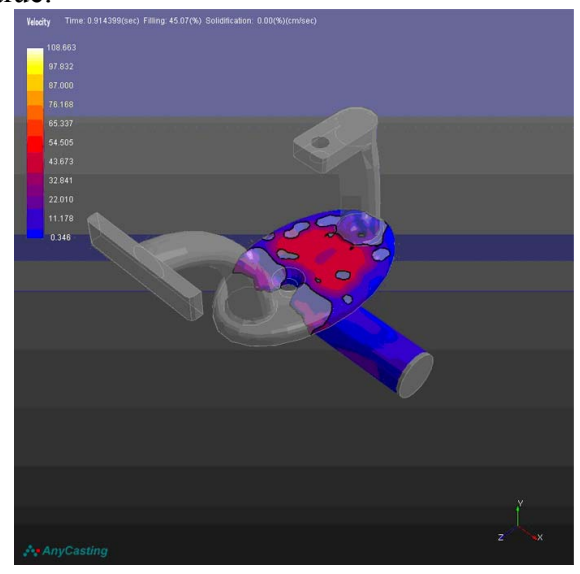

Figure 5. The speed of filling process when thickness of ingates is $2 \mathrm{~mm}$, the injection speed is $0.1 \mathrm{~m} / \mathrm{s}$

Mould ingate's thickness and ejection velocity are co-determining semi-solid metal paste filling mold state. It's easy to obtain laminar filling mode for semi-solid metal slurry when the ingate is thicker, and the injection speed is lower. It's also easy to produce turbulence and splash phenomenon near the ingate for semi-solid metal slurry when the ingate is thinner and the injection speed is higher. Although we can reduce ingate dimension and slow down the injection speed to obtain a relatively steady filling process, it will increase the filling time inevitably, which is not good for the die-casting filling, and will cool the metal slurry so much that will have some misrun defects.

In all, semi-solid metal slurry filling process will be ideal when the ingate's thickness is $7 \mathrm{~mm}$, and the injection speed in the low speed phase is $0.1 \mathrm{~m} / \mathrm{s}$.

2) The influence of high-speed switching time and injection speed in high speed phase: Figure 6. and Figure 7. show the simulated results when the ingate's thickness is $7 \mathrm{~mm}$, and injecting speed in low speed phase is $0.1 \mathrm{~m} / \mathrm{s}$, and switching in high speed when the filling mold rate is $30 \%$. Figure. 6 shows the simulated result when it fills to $40 \%$, while Figure 7 . shows when $75 \%$. From the figures, we can find that it appeared turbulent phenomenon in the base cavity and crank of hooks when we switch the speed in the filling rate of $30 \%$ and the metal slurry is just through the ingate. Figure 8. and Figure 9. show the simulated results when the injection speed in high speed is $5 \mathrm{~m} / \mathrm{s}$ and the filling rate is $55 \%$ and $85 \%$. We can get from the figures that it's easy to form blowholes at the hook's base (Figure 10.), and it appears a backflow state clearly in filling the crank when the injecting speed in high speed phase, and the speed of metal slurry is too high after getting through the ingate. However, it is stable for the filling metal slurry, and not been observed of the blowhole appearing when the injecting speed in high speed phase is $1 \mathrm{~m} / \mathrm{s}$.It follows that it will have an ideal filling process when the injecting speed in high speed phase is $1 \mathrm{~m} / \mathrm{s}$.

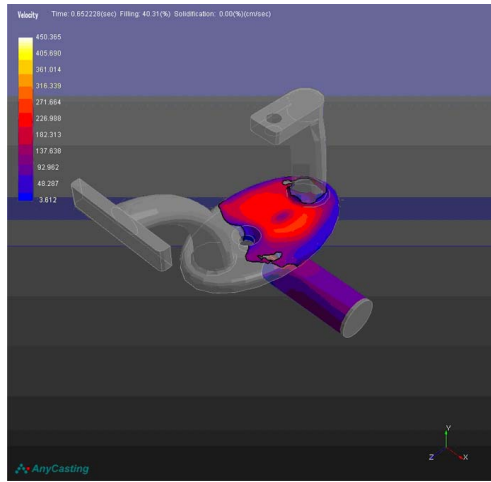

Figure 6. Injection speed is $0.1 \mathrm{~m} / \mathrm{s} \quad$ And filling rate is $40 \%$

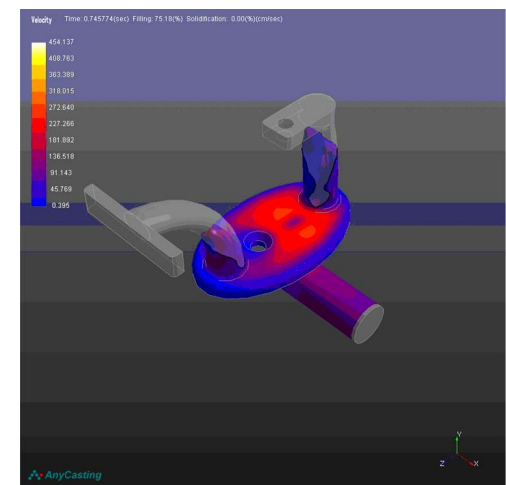

Figure 7. Injection speed is $0.1 \mathrm{~m} / \mathrm{s}$ And filling rate is $75 \%$

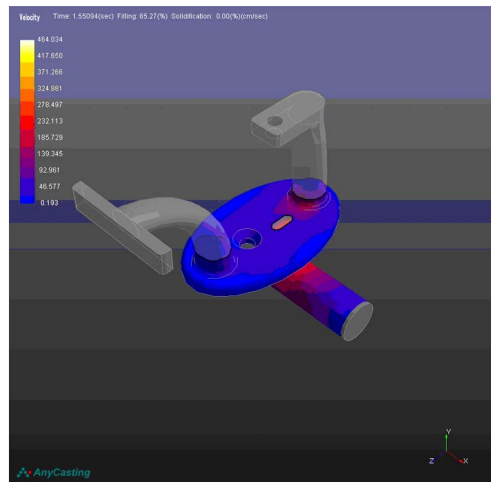

Figure 8 . Injection speed is $5 \mathrm{~m} / \mathrm{s}$ And filling rate is $55 \%$ 


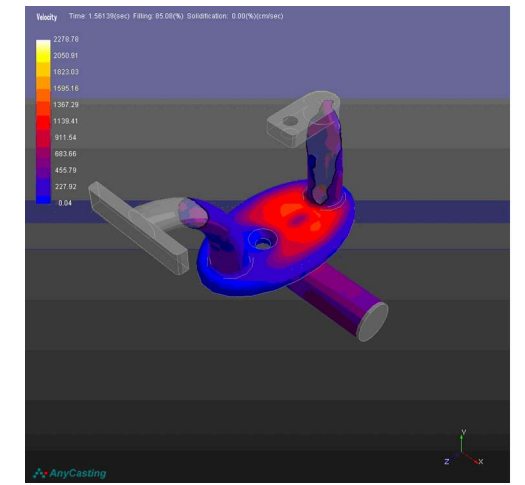

Figure 9 . Injection speed is $5 \mathrm{~m} / \mathrm{s}$ And filling rate is $85 \%$

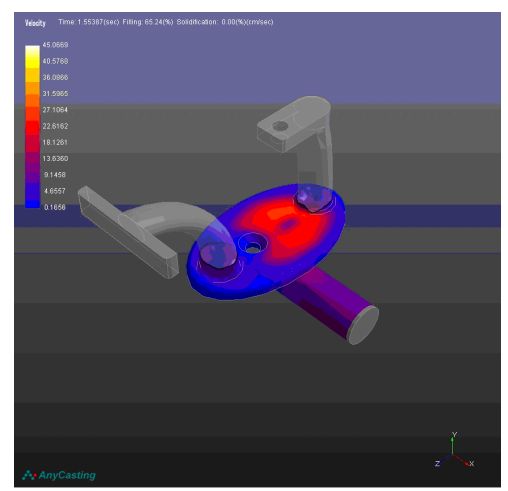

Figure 10. Injection speed is $1 \mathrm{~m} / \mathrm{s}$ And filling rate is $55 \%$

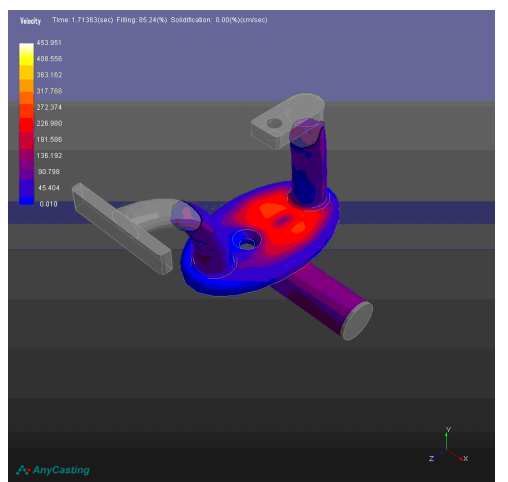

Figure 11. Injection speed is $1 \mathrm{~m} / \mathrm{s}$ And filling rate is $85 \%$

3) Filling sequence, solidification sequence and defect analysis: Figure. 12 is the filling mold sequence of the casting. We can find that the filling process is stable by the craft after the simulation and optimization. It's a filling way which is similar to the "whole wall thickness", and it takes about $1.74 \mathrm{~s}$.

The solidification sequence of the casting is that the casting's base is the first, then the crank, and the sorue is the last. The all time of the solidification takes about $3.9 \mathrm{~s}$. We can also find that the probability of defects is large in the finally filling mold place of the crank and the pouring gate. The pouring gate is excess material, which will be cut off after filling, and the defects existing in the finally filling mold place of the crank can be cleaned by setting overflow and exhaust system.

It shows by the simulated results that the castings' quality is influenced by the ingate's thickness, injection speed in high and low speed phase and the switch time of high speed phase. Through the contrast and analysis of the simulation results, we found that the castings' quality is the best when the ingate's thickness is $7 \mathrm{~mm}$, and the injection speed in low speed phase is $0.1 \mathrm{~m} / \mathrm{s}$, the injection speed in high speed phase is $1 \mathrm{~m} / \mathrm{s}$ and the switch time of high speed is $65 \%$ filling rate. The surface of the semi-solid die-casting parts is smooth. As a result, semi-solid magnesium alloys on pressure chamber piston high-pressure has very good liquidity, the same as Magnesium alloys Newton fluid, which can fill in the cavity beautifully, under the reasonable technical parameters.

\section{SUMMARIES}

Through the above analysis, the following results could be obtained:

1) Solid-phase scores and shearing speed are the important factors to influence the apparent viscosity of semi-solid magnesium alloy. The value of the apparent viscosity increases with the increase of solid-phase scores, decreases with the increase of shearing speed.

2) When the slurry is made by mechanical agitation, the semi-solid magnesium alloy has good rheological properties in the mixing temperature for $570^{\circ} \mathrm{C}$ and the shearing speed for $88.85 \mathrm{~s}^{-1}$.

3) It is good to increase the ingate's thickness in semi-solid casting in order to avoid the defects of pore and shrinkage porosity and get the filling mold way of laminar flow in the semi-solid metal slurry filling, because the mobility of semi-solid metal slurry is not as good as liquid metal.

4) For the magnesium alloy hooks of trains in the study, the casting has good rheological properties and idea quality when the injection speed in low speed is $0.1 \mathrm{~m} / \mathrm{s}$, the injection speed in high speed is $1 \mathrm{~m} / \mathrm{s}$, and the switch speed in the filling rate is $65 \%$ by the numerical simulation.

\section{REFERENCES}

[1] R.E. Brown. Magnesium 2000 Second Israeli Int Conference on Magnesium Science and Technology. Light Metal Age, 2000; 58(7-8): $100 \sim 103$.

[2] R.L. Edgar. Global Overview on Demand and Applications for Magnesium Alloys. In: Kainer K U (Ed.). Proc Magnesium Alloys and Their Applications. Wolfsburg, Germany, 2000;3 $\sim 8$.

[3] R. Brown. Australian Magnesium Projects-Update. Light Metal Age, 2000; (9-10):54 57.

[4] C.P. Chen, C.-Y.A. Tsao. Microstructure evolution of previously deformed ZA27 alloy during partial remelting. Materials Science and Engineering A,2002;(337):73 81.

[5] T.J. Chen, Y. Hao, J. Sun, Y.D. Li. Effects of processing parameters on tensile properties and hardness of thixoformed ZA27 alloy. Materials Science and Engineering A,2004;(382):90 103 . 
[6] D.G. Eskin, Suyitno, L. Katgerman. Mechanical properties in the semi-solid state and hot tearing of Aluminum alloy. Process in Materials Science,2004;49(5):629 711.

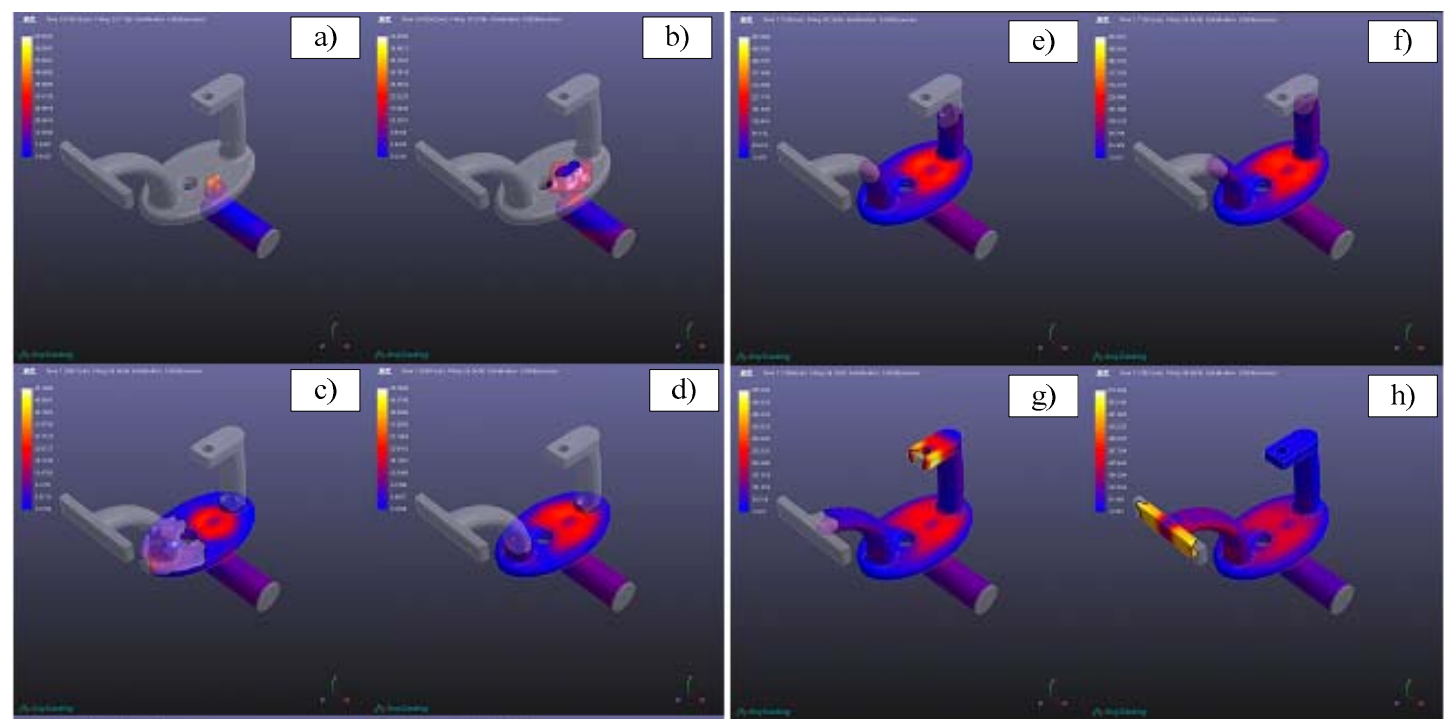

Figure 12. The filling mold sequence 